\title{
Room-Temperature Freeze Casting for Ceramics with Nonaqueous Sublimable Vehicles in the Naphthalene-Camphor Eutectic System
}

\author{
Kiyoshi Araki* and John W. Halloran ${ }^{\star *}$ \\ Department of Materials Science and Engineering, University of Michigan, Ann Arbor, Michigan 48109
}

\begin{abstract}
Freeze casting for $\mathrm{Al}_{2} \mathrm{O}_{3}$ was accomplished at room temperature with nonaqueous sublimable vehicles in the naphthalenecamphor eutectic system with a eutectic temperature of $31^{\circ} \mathrm{C}$. A fully dense sintered body ( $>99.5 \%$ of theoretical density (T.D.)) was obtained with a eutectic composition vehicle, whereas at most $90 \%$ T.D. was obtained with an off-eutectic (i.e., hypo- or hypereutectic) composition vehicle due to formation of large uniquely shaped voids. Microstructural observation suggested that growing pro-eutectic crystals rejected the suspended $\mathrm{Al}_{2} \mathrm{O}_{3}$ particles to form large voids during the solidification process. At the eutectic composition, formation of fine lamellar microstructure in a solidified vehicle is considered to inhibit particle rejection resulting in large voids.
\end{abstract}

\section{Introduction}

$F^{e}$ REEZE casting followed by a freeze-drying process ${ }^{1,2}$ has been used in complex-shape forming for ceramics, like other colloidal processing techniques such as conventional slip casting, injection molding, and gel casting. ${ }^{3-5}$ The details of these colloidal ceramic processing techniques were recently reviewed. ${ }^{6-8}$ Freeze casting is a forming technique where a ceramic slurry, which is usually aqueous and sometimes containing silica-sol, is frozen in a mold under extremely cold temperature, e.g., $<-40^{\circ} \mathrm{C}$, and followed by demolding and vehicle removal by sublimation, i.e., freeze-drying, to obtain a green body. This technique has many advantages such as a fast manufacturing cycle, no drying cracks, no troublesome binder burnout process, and so on. However, in the freeze casting technique, we need special efforts to obtain an extremely cold temperature, e.g., $<-40^{\circ} \mathrm{C}$.

To eliminate this expensive freezing process under extremely cold temperature and troublesome freeze-drying under $0^{\circ} \mathrm{C}$, the authors have recently developed a new freeze casting technique capable of manufacturing near room temperature using a molecular compound, camphene $\left(\mathrm{C}_{10} \mathrm{H}_{16}\right)$, as a vehicle and showed that an almost fully dense $\mathrm{Al}_{2} \mathrm{O}_{3}$ sintered body was obtained. ${ }^{9}$ Since camphene is a natural, nontoxic material, this technique is even environmentally friendly unlike other room-temperature freeze casting techniques ${ }^{10,11}$ with toxic materials as a vehicle. Among such materials, naphthalene $\left(\mathrm{C}_{10} \mathrm{H}_{8}\right)$ and camphor $\left(\mathrm{C}_{10} \mathrm{H}_{16} \mathrm{O}\right)$ are promising candidates for a vehicle of room-temperature freeze casting, even though they are a little toxic, because they have (1) low liquid viscosity as water so that concentrated slurries can be made, (2) negative volume change (shrinkage) during solidification unlike water to contribute a higher green density, and (3) higher vapor pressure in a solid state for easy freeze-drying. Their properties, ${ }^{12,13}$ as well as those of water, ${ }^{14}$ are summarized in Table I. However, their solidification temperatures, especially

C.-H. Hsueh-contributing editor

\footnotetext{
Manuscript No. 10706. Received December 1, 2003; approved July 6, 2004

${ }^{*}$ Member, American Ceramic Society.

${ }^{\star *}$ Fellow, American Ceramic Society.
}

$180^{\circ} \mathrm{C}$ for camphor, are too high for room-temperature freeze casting where the preferable solidification temperature range is $30-60^{\circ} \mathrm{C}$.

The binary system of naphthalene and camphor, both of which are molecular compounds, is a known eutectic system with a eutectic temperature of $31-32^{\circ} \mathrm{C} .{ }^{15,16}$ The phase diagram of the naphthalene-camphor system by Robinson et al. ${ }^{16}$ is shown in Fig. 1. Because of the convenient eutectic temperature, the naphthalene-camphor alloy has been studied by metallurgists as a model for solidification. ${ }^{17-19}$ This eutectic alloy seems suitable for a vehicle for room-temperature freeze casting in terms of not only a convenient solidification temperature of $31-32^{\circ} \mathrm{C}$ but also a low liquid viscosity, negative volume change during solidification, and higher vapor pressure, all of which are expected from the properties of pure naphthalene and pure camphor.

In this paper, we report the trial of using a eutectic vehicle for room-temperature freeze casting for ceramics. The eutectic naphthalene-camphor alloy with a manageable solidification temperature is chosen as a vehicle. We also investigate the effect of vehicle composition (eutectic or off-eutectic) on the microstructure of final sintered ceramics.

\section{Experimental Procedure}

\section{(1) Materials}

We chose alumina as a ceramic example, using a common $\alpha-\mathrm{Al}_{2} \mathrm{O}_{3}$ powder (AG16, Alcoa Chemical, Pittsburgh, PA) with a median size $\left(d_{50}\right)$ of $0.4 \mu \mathrm{m}$, a specific surface area of $8.6 \mathrm{~m}^{2} / \mathrm{g}$, and a density of $3.91 \mathrm{~g} / \mathrm{cm}^{3}$ (all from the manufacturer's specifications). As a vehicle, naphthalene $\left(>99.6 \%, \mathrm{C}_{10} \mathrm{H}_{8}\right.$, Alfa Aesar, Ward Hill, MA) with a melting temperature of $80^{\circ} \mathrm{C}$ (from the manufacturer's specifications) and DL-camphor (>96\%, $\mathrm{C}_{10} \mathrm{H}_{16} \mathrm{O}$, Alfa Aesar/Avocado Organics, Ward Hill, MA) with a melting temperature of $173-175^{\circ} \mathrm{C}$ (from the manufacturer's specifications) were used without further purification. To produce stable $\mathrm{Al}_{2} \mathrm{O}_{3}$ suspensions, a commercial liquid product of amine derivative of a fatty acid condensation polymer (Perfad 9100, UNIQEMA, Everburg, Belgium) with a measured density of 0.963 $\mathrm{g} / \mathrm{cm}^{3}$ was adopted as the colloidal dispersant.

\section{(2) Fabrication Procedure}

First, three kinds of liquid vehicles with either (1) hypoeutectic (naphthalene-rich), (2) eutectic, or (3) hypereutectic (camphorrich) composition in the naphthalene-camphor eutectic system was prepared. Appropriate amounts of solid naphthalene, solid camphor, and a liquid dispersant were put into high-density polyethylene bottles with $\mathrm{Al}_{2} \mathrm{O}_{3}$ milling media. They were sealed and ball-milled inside a drying oven for $1 \mathrm{~h}$ at $55^{\circ} \mathrm{C}$ for hypoeutectic and eutectic composition, and at $60^{\circ} \mathrm{C}$ for hypereutectic composition to make liquid vehicles made of a molten naphthalene-camphor alloy and dispersant. After confirming that the vehicles became completely liquid, an appropriate amount of prewarmed $\mathrm{Al}_{2} \mathrm{O}_{3}$ powder was added into the liquid vehicles, and they were again ball-milled inside the same drying oven at the same temperatures for $20 \mathrm{~h}$ to produce stable, dispersed slurries. Slurries with initial solid content of $20,30,40$ and $48 \mathrm{vol} \%$, all 
Table I. Some Physical Properties of Naphthalene, Camphor, and Water

\begin{tabular}{llcccc}
\hline & $\begin{array}{c}\text { Chemical } \\
\text { formula }\end{array}$ & $\begin{array}{c}\text { Solidification } \\
\text { temperature }\left({ }^{\circ} \mathrm{C}\right)\end{array}$ & $\begin{array}{c}\text { Volume change } \\
\text { during solidification }\end{array}$ & Liquid viscosity (mPa·s) & Vapor pressure in solids (Pa) \\
\hline $\begin{array}{l}\text { Naphthalene } \\
\text { Camphor }\end{array}$ & $\mathrm{C}_{10} \mathrm{H}_{8}$ & 80 & Negative & $0.91\left(80^{\circ} \mathrm{C}\right)$ & $1.3 \times 10^{2}\left(52^{\circ} \mathrm{C}\right)$ \\
Water & $\mathrm{C}_{10} \mathrm{H}_{16} \mathrm{O}$ & 180 & Negative & $0.63\left(180^{\circ} \mathrm{C}\right)$ & $1.3 \times 10^{2}\left(41^{\circ} \mathrm{C}\right)$ \\
& $\mathrm{H}_{2} \mathrm{O}$ & 0 & Positive & $1.0\left(20^{\circ} \mathrm{C}\right)$ & $1.3 \times 10^{2}\left(-20^{\circ} \mathrm{C}\right)$ \\
\hline
\end{tabular}

with $3 \mathrm{wt} \%$ dispersant (to $100 \mathrm{wt} \% \mathrm{Al}_{2} \mathrm{O}_{3}$ powder), were prepared in $10-20 \mathrm{~cm}^{3}$ batches.

During the warm ball-milling process, the naphthalene vapor and the camphor vapor in the sealed bottle should be in equilibrium with the slurry. Because the naphthalene vapor pressure and the camphor vapor pressure are different and these vapors are lost when the bottle is opened, the naphthalene ratio to camphor in the warm ball-milled slurries will be changed from the initial charged ratio. As is explained in detail later, microstructural observation of solidified naphthalene-camphor alloys revealed that the initial charge of $40 \mathrm{wt} \%$ naphthalene-60 wt $\%$ camphor became the eutectic composition, which is $35 \mathrm{wt} \%$ naphthalene-65 wt $\%$ camphor according to the phase diagram, ${ }^{16}$ after the warm ballmilling in this work. Initial charges of $56 \mathrm{wt} \%$ naphthalene-44 wt $\%$ camphor, $40 \mathrm{wt} \%$ naphthalene-60 wt $\%$ camphor, and 31 wt \% naphthalene-69 wt\% camphor were used as hypoeutectic, eutectic, and hypereutectic vehicles, respectively. Measured liquid densities of hypoeutectic (56 wt $\%$ naphthalene-44 wt $\%$ camphor) and eutectic (40 wt\% naphthalene-60 wt\% camphor) compositions are both $0.983 \mathrm{~g} / \mathrm{cm}^{3}$ at $55^{\circ} \mathrm{C}$, and that of hypereutectic $(31$ wt\% naphthalene-69 wt\% camphor) composition is $0.964 \mathrm{~g} / \mathrm{cm}^{3}$ at $60^{\circ} \mathrm{C}$. Examples of the charged weight of each material for 48 vol\% $\mathrm{Al}_{2} \mathrm{O}_{3}$ slurries are shown in Table II.

Warm ball-milled slurries were poured into a cylindrical depression on the surface of polyurethane molds at room temperature. The size of the mold was $10 \mathrm{~mm}$ in diameter and $5 \mathrm{~mm}$ in depth. The slurries solidified typically within 20 min to yield solid rigid green bodies. After demolding, green bodies were placed in ambient atmosphere with an airflow rate of $0.01-0.05 \mathrm{~m} / \mathrm{s}$ to sublime the frozen naphthalene-camphor alloy from the green

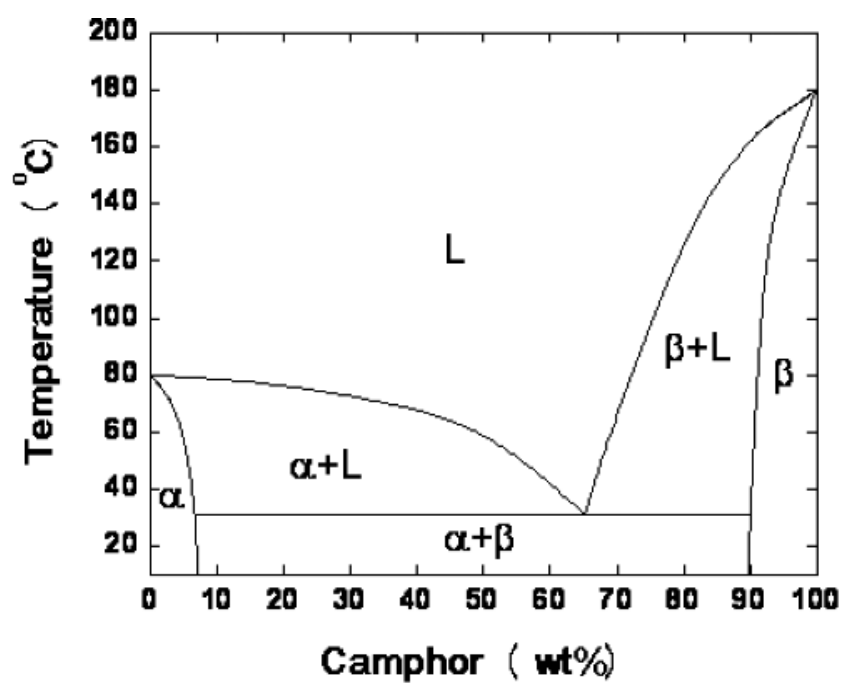

Fig. 1. Naphthalene-camphor phase diagram. ${ }^{16}$ bodies. Judging from the weight change, this sublimation process typically finished in $60 \mathrm{~h}$. During this freeze-drying process, neither crack formation nor measurable shrinkage was observed. After the freeze-drying process, the cast bodies were sintered at $1600^{\circ} \mathrm{C}$ (ramping rate of $5^{\circ} \mathrm{C} / \mathrm{min}$ ) for $4 \mathrm{~h}$ without a special binder burnout process. The fabrication procedure described above is summarized in Fig. 2.

\section{(3) Characterization}

The density of sintered bodies was measured using the water displacement method based on the Archimedean principle. The microstructure of the sintered bodies was observed with scanning electron microscopy (SEM; XL-30, Philips Electronics N.V., Eindehoven, The Netherlands). The microstructure of solidified naphthalene-camphor alloys was observed with optical microscopy (OM; BH2-UMA, Olympus, Tokyo, Japan) in the transmission mode by dropping molten liquid alloys without ceramic powder and the dispersant onto a slide glass.

\section{Results and Discussion}

Figure 3 shows the relative density of $\mathrm{Al}_{2} \mathrm{O}_{3}$ sintered bodies as a function of the charged solid content $\left(\mathrm{Al}_{2} \mathrm{O}_{3}\right.$ volume fraction) in

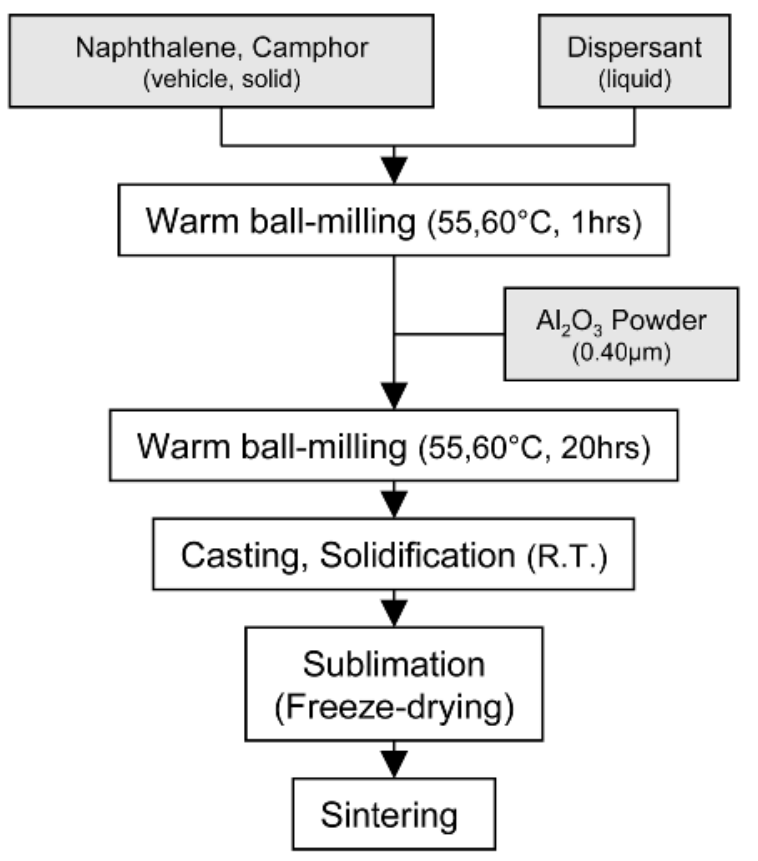

Fig. 2. Schematic chart of the fabrication procedure.

Table II. Example of the Charged Weight for 48 vol\% $\mathrm{Al}_{2} \mathrm{O}_{3}$ Slurries

\begin{tabular}{llcccc}
\hline & Naphthalene-to-camphor ratio & $\mathrm{Al}_{2} \mathrm{O}_{3}(\mathrm{~g})$ & Dispersant $(\mathrm{g})$ & Naphthalene $(\mathrm{g})$ & Camphor $(\mathrm{g})$ \\
\hline Hypoeutectic & $56 \mathrm{wt} \% \mathrm{~N}-44 \mathrm{wt} \% \mathrm{C}$ & 41.37 & 1.24 & 5.60 & 4.40 \\
Eutectic & $40 \mathrm{wt} \% \mathrm{~N}-60 \mathrm{wt} \% \mathrm{C}$ & 41.37 & 1.24 & 4.00 & 6.00 \\
Hypereutectic & $31 \mathrm{wt} \% \mathrm{~N}-69 \mathrm{wt} \% \mathrm{C}$ & 42.18 & 1.27 & 3.10 & 6.90 \\
\hline
\end{tabular}




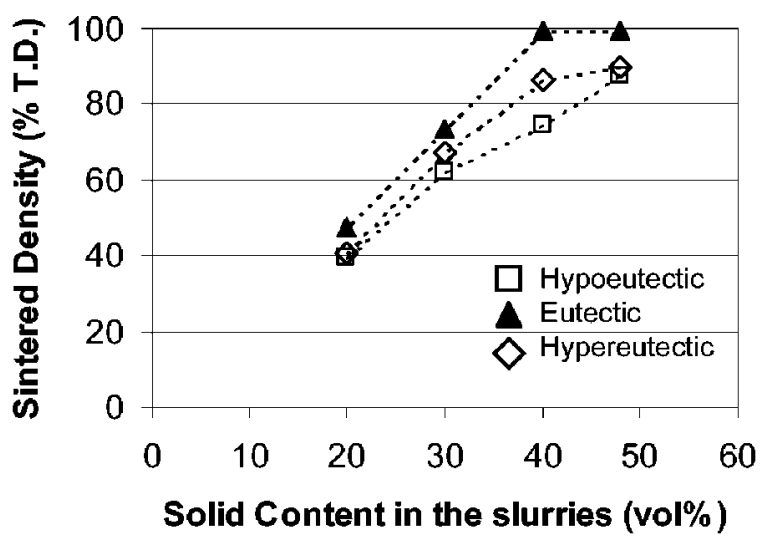

Fig. 3. Relative density of $\mathrm{Al}_{2} \mathrm{O}_{3}$ sintered bodies as a function of the charged solid content in the slurries.

the slurries with hypoeutectic, eutectic, and hypereutectic compositions. Almost fully dense bodies ( $>99.5 \%$ of theoretical density (T.D.)) were obtained from the 48 vol\% slurry with eutectic composition. It is noted that even 40 vol\% slurry with eutectic composition gives sintered bodies with more than 98\% T.D. However, at most around 90\% T.D. was obtained from 48 vol\% slurries, which were practically almost at maximum solid content in this work, with hypo- and hypereutectic compositions.
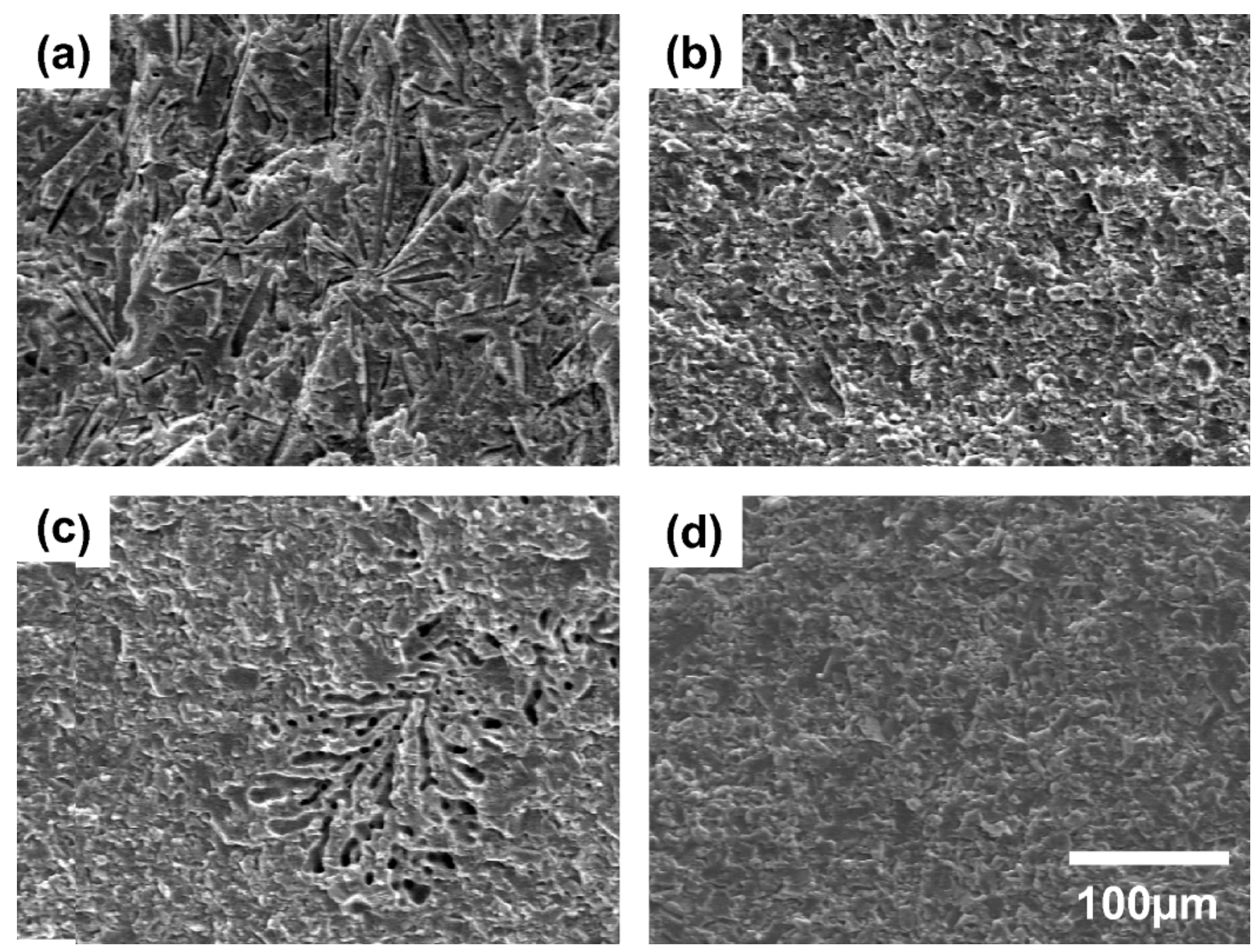

Fig. 4. Fracture surface of sintered bodies from (a) hypoeutectic, (b) eutectic, and (c) hypereutectic composition slurries. Fracture surface of sintered body by (d) uniaxial dry pressing at $200 \mathrm{MPa}$ is also shown as a comparison. 

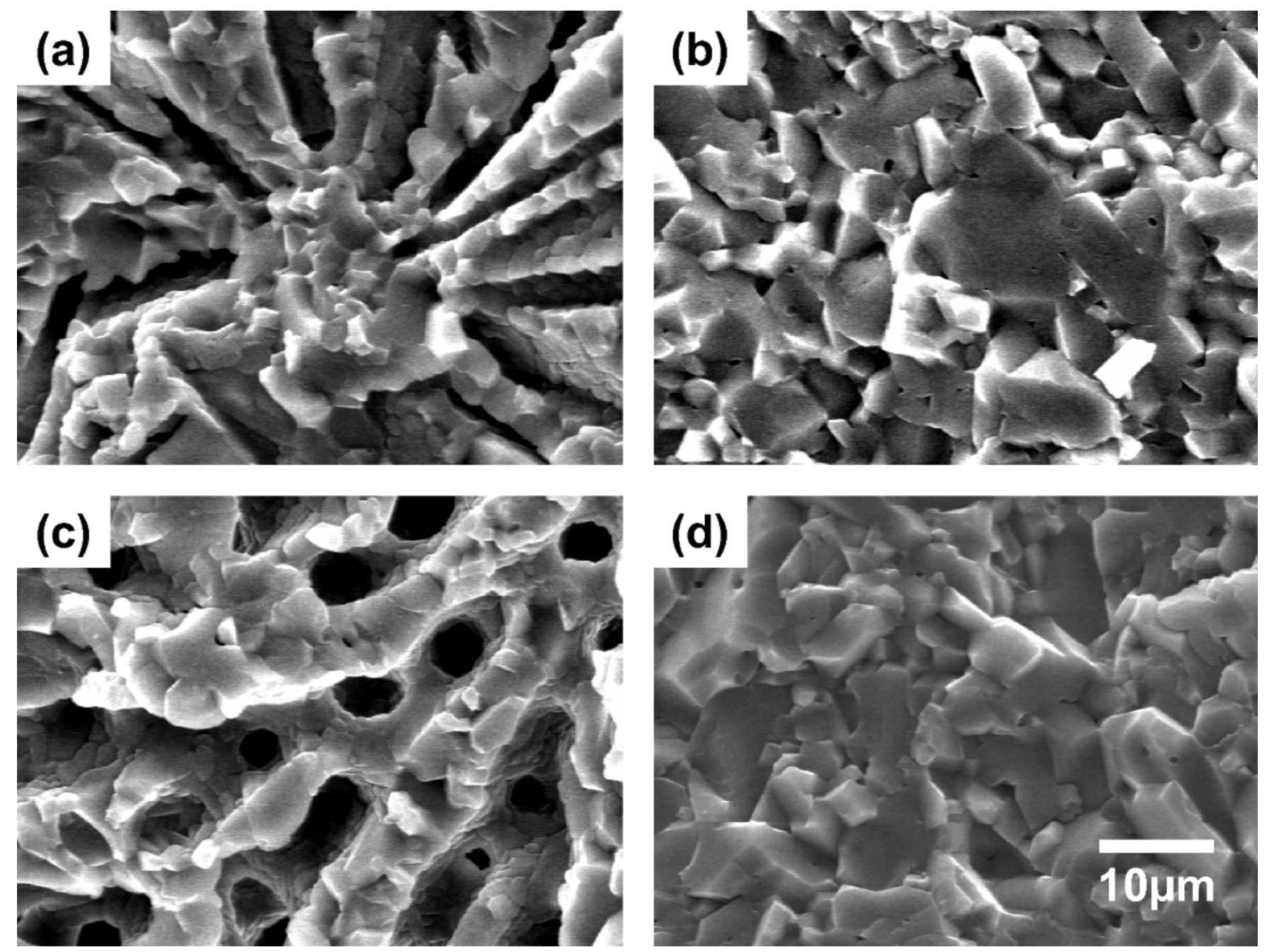

Fig. 5. Fracture surface of sintered bodies from (a) hypoeutectic, (b) eutectic, and (c) hypereutectic composition slurries. Fracture surface of sintered body by (d) uniaxial dry pressing at $200 \mathrm{MPa}$ is also shown as a comparison. Magnification in this figure is higher than that in Fig. 4 .

Almost uniform microstructure is observed in the solidified eutectic alloy, as shown in Fig. 6(b). On the other hand, a lot of faceted long plates surrounded by a matrix region are observed in the solidified hypoeutectic alloy, as shown in Fig. 6(a). Precipitates shaped like six-pointed stars are observed also in the solidified hypereutectic alloy, as shown in Fig. 6(c).

According to the naphthalene-camphor phase diagram (Fig. 1), the long-plate-shaped precipitates in the hypoeutectic composition (Fig. 6(a)) and the six-pointed-star-shaped precipitates in the hypereutectic composition (Fig. 6(c)) are considered as proeutectic naphthalene-rich phase, $\alpha$, and pro-eutectic camphor-rich phase, $\beta$, respectively. The faceted plate morphology of the pro-eutectic naphthalene-rich phase, which is almost the same as the one in Fig. 6(a), in the naphthalene-camphor system has been observed and well described by many researchers. ${ }^{16-19}$ As for the pro-eutectic camphor-rich phase in this system, six-pointed-starshaped precipitates, which were the same as the ones in Fig. 6(c), were observed by Robinson et al. ${ }^{16}$ They also observed that the growth of precipitates with initial six-pointed-star shapes tended to be dendritic in the latter stages of precipitation. ${ }^{16}$

As for large voids, it is well known that large voids are formed during freezing because of rejection of suspended particles by large ice crystals, which sometimes exhibit dendritic growth, in the aqueous freeze casting technique. ${ }^{20-22}$ It is also known that rejection of ceramic particles by growing crystals occurs also in nonaqueous media during solidification. ${ }^{23}$ The authors actually showed that, in an $\mathrm{Al}_{2} \mathrm{O}_{3} /$ molten camphene $\left(\mathrm{C}_{10} \mathrm{H}_{16}\right)$ slurry with relatively low solid contents, the suspended particles are rejected by growing camphene dendrites to form large voids, which well replicate the shape of large camphene dendritic crystals, during freezing. ${ }^{24}$

From the above discussion, it seems reasonable that large uniquely shaped voids in $\mathrm{Al}_{2} \mathrm{O}_{3}$ sintered bodies from off-eutectic composition slurries are formed by the rejection of suspended particles by growing pro-eutectic crystals. Indeed, the long-plateshaped voids (Figs. 4(a) and 5(a)) in sintered bodies from hypoeutectic composition slurry well replicate the faceted plate morphology of pro-eutectic naphthalene-rich phase ${ }^{16-19}$ (Fig. 6(a)). The dendrite-shaped voids (Figs. 4(c) and 5(c)) in sintered bodies from hypereutectic composition slurry are considered to replicate the dendritic morphology of pro-eutectic camphor-rich crystals, ${ }^{16}$ which are in the latter stage of the growth of the six-pointed-starshaped precipitates (Fig. 6(c)).

Even though there were no pro-eutectic crystals in the eutectic composition slurry, however, large voids could be formed in sintered bodies from the eutectic composition slurry. Since, as described earlier, large voids are often observed ${ }^{20-22,24}$ in sintered bodies from one component vehicle slurry which has no proeutectic crystals, even non-pro-eutectic crystals could form large voids. To investigate the reason why there are no large voids in the sintered body from the eutectic slurry, further microstructural investigation was conducted for the solidified naphthalene-camphor alloy with the eutectic composition. Optical microscopy with a polarizer revealed that the eutectic has a little disordered lamellar microstructure of the naphthalene-rich and camphor-rich phases, and the lamellar spacing, which should be dependent on the cooling rate, ${ }^{16}$ was about $10 \mu \mathrm{m}$, as shown in Fig. 7 . Thus, in the 

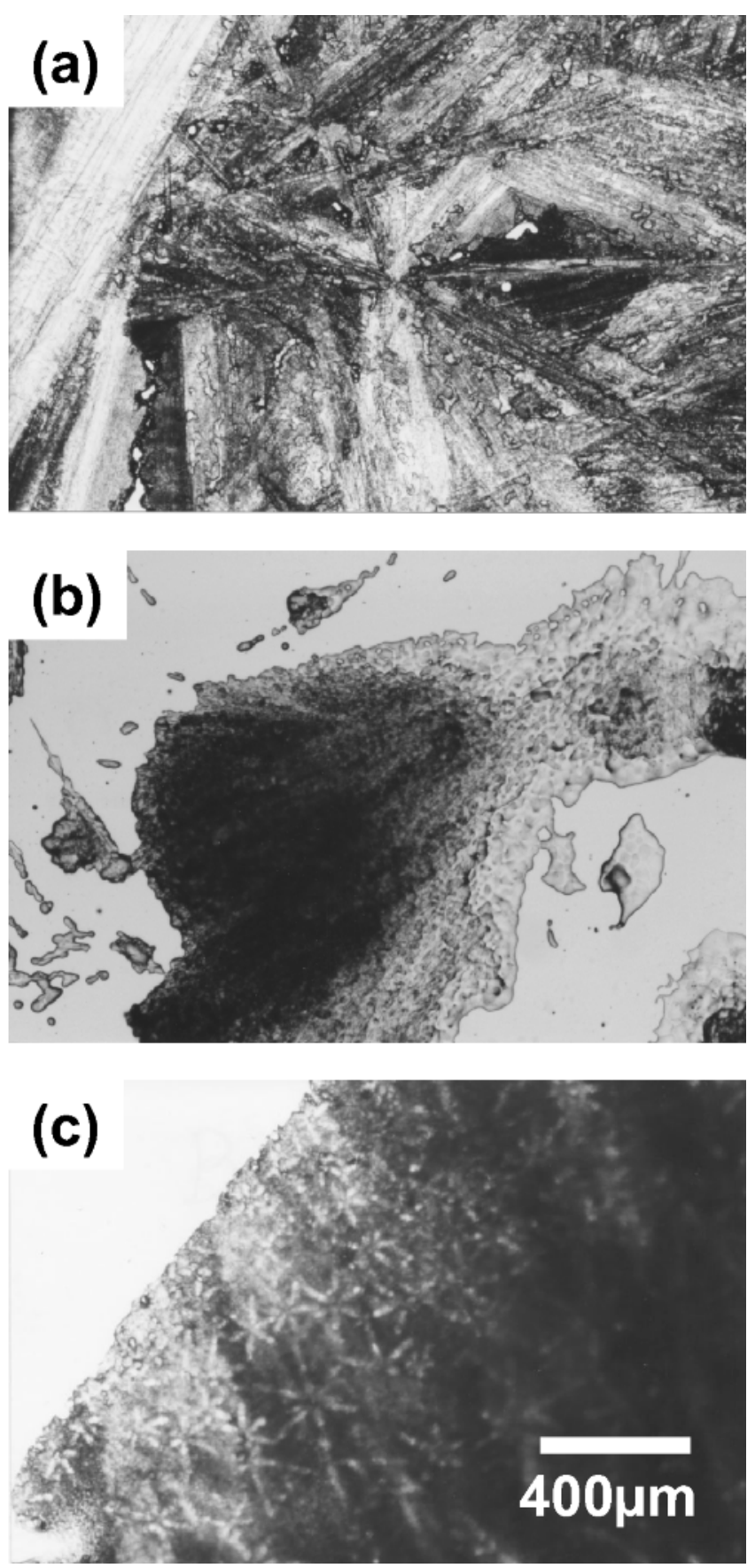

Fig. 6. Typical solidified microstructure of (a) hypoeutectic, (b) eutectic, and (c) hypereutectic alloys in the naphthalene-camphor system.

eutectic composition slurry, the formation of fine lamellar microstructure is considered to inhibit particle rejection, resulting in large voids. The effect of vehicle composition (eutectic or offeutectic) on the microstructure of naphthalene-camphor alloys and final sintered ceramics is schematically summarized in Fig. 8.

In aqueous freeze casting, to avoid the formation of large ice crystals, cryoprotectants ${ }^{20-22}$ such as dimethyl sulfoxide, sugar, glycerin, and glycerol are often added to the slurry. These cryoprotectants are considered to bind to water molecules and disrupt the complete crystallization of ice, resulting in a localized amorphous structure, thus reducing the size of growing crystals and inhibiting particle rejection. ${ }^{22}$ Formation of fine lamellar microstructure in a solidified slurry with eutectic composition vehicle in this work can be another concept for inhibiting particle rejection in freeze casting technique, especially with sublimable organic vehicles.
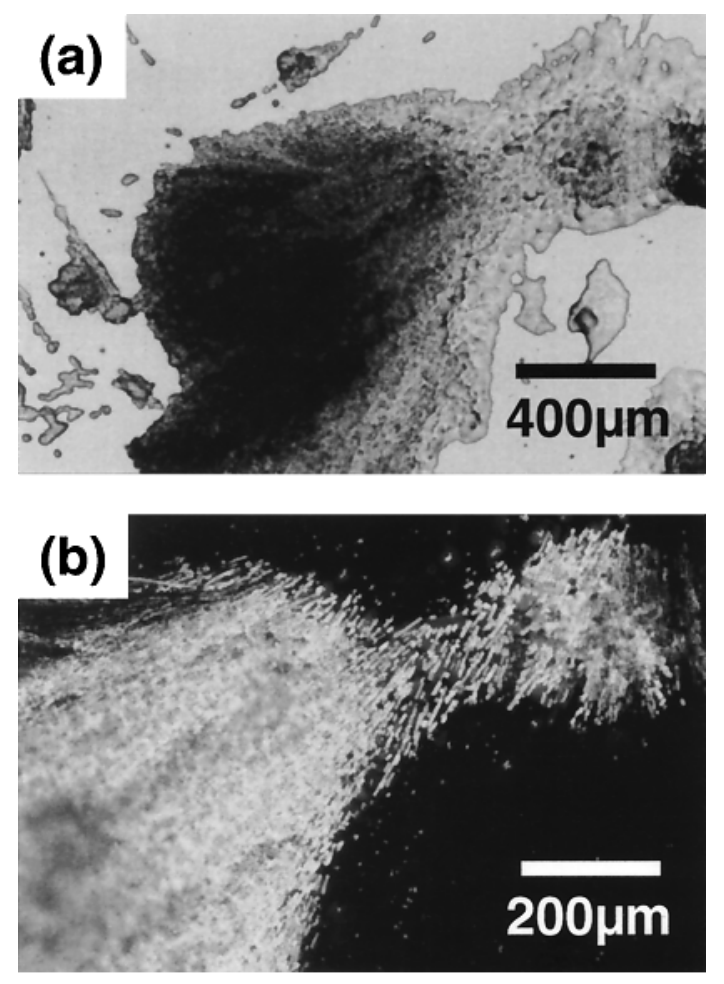

Fig. 7. Solidified microstructures of naphthalene-camphor alloy with the eutectic composition observed by an optical microscope (a) without and (b) with a polarizer. A distorted lamellar microstructure with a spacing of about $10 \mu \mathrm{m}$ is observed on the center in (b).

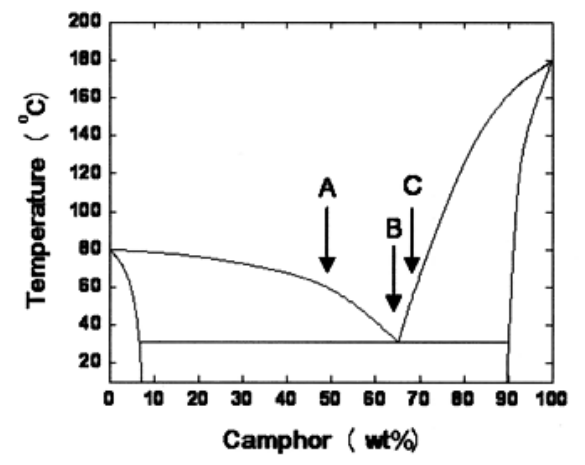

\section{$\begin{array}{ccc}\text { A } & \text { B } & \text { C } \\ \text { Hypoeutectic } & \text { Eutectic } & \text { Hypereutectic }\end{array}$}

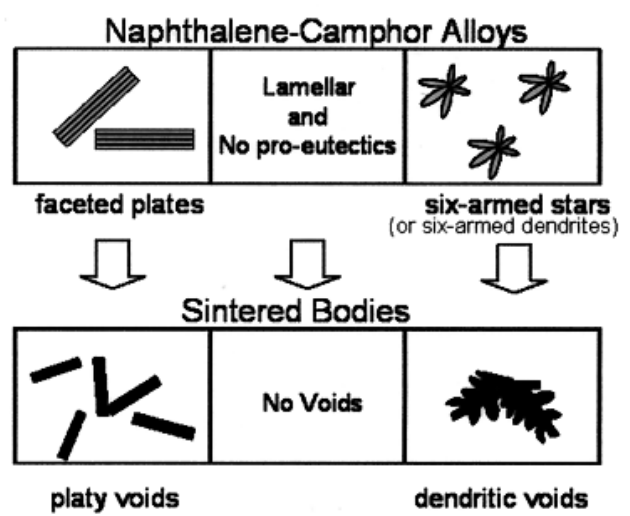

Fig. 8. Schematic drawings of the effect of composition on microstructures in the naphthalene-camphor solidified alloys and resulting sintered bodies. Pro-eutectics in off-eutectic composition result in voids in sintered bodies. 


\section{Summary}

Freeze casting for $\mathrm{Al}_{2} \mathrm{O}_{3}$ was accomplished at room temperature with nonaqueous sublimable vehicles in the naphthalenecamphor eutectic system with a eutectic temperature of $31^{\circ} \mathrm{C}$. Three kinds of vehicles were prepared: (1) hypoeutectic (naphthalene-rich), (2) eutectic, and (3) hypereutectic (camphorrich) composition vehicles. An almost fully dense sintered body (>99.5\% T.D.) was obtained with the eutectic composition vehicle, whereas at most $90 \%$ T.D. was obtained with the off-eutectic (i.e., hypo- or hypereutectic) composition vehicle due to formation of large uniquely shaped voids. Long-plate-shaped voids and distorted dendrite-shaped voids were observed in sintered bodies from hypoeutectic and hypereutectic composition vehicles, respectively. Microstructural observation suggested that growing proeutectic crystals, i.e., naphthalene-rich $\alpha$-phase and camphor-rich $\beta$-phase, respectively, rejected the suspended $\mathrm{Al}_{2} \mathrm{O}_{3}$ particles to form large voids during the solidification (freezing) process. At the eutectic composition vehicle, formation of distorted fine lamellar microstructure and no pro-eutectic crystals were observed. The fine lamellar microstructure is considered to inhibit particle rejection resulting in large voids. Like cryoprotectant addition to the slurry, adopting a eutectic composition vehicle can be another concept for inhibiting particle rejection in freeze casting, especially with sublimable molecular compound vehicles.

\section{References}

${ }^{1}$ H. Ballman "Unique New Forming Technique," Ceram. Age, 791, 36-38 (1957). ${ }^{2}$ B. E. Novich, C. A. Sundback, and R. W. Adams, "Quickset Injection Molding of High-Performance Ceramics"; pp. 157-64 in Ceramic Transactions, Vol. 26, Forming Science and Technology for Ceramics. American Ceramic Society, Westerville, $\mathrm{OH}, 1992$.

${ }^{3}$ O. O. Omatete, M. A. Janney, and R. A. Strehlow, "Gelcasting-A New Ceramic Forming Process," Am. Ceram. Soc. Bull., 70 [10] 1641-49 (1991).

${ }^{4}$ A. C. Young, O. O. Omatete, M. A. Janney, and P. A. Menchhofer, "Gelcasting of Alumina," J. Am. Ceram. Soc., 74 [3] 612-18 (1991).
${ }^{5}$ S. Morissette and J. A. Lewis, "Chemorheology of Aqueous Alumina-Poly(vinyl alcohol) Gelcasting Suspensions," J. Am. Ceram. Soc., 82 [3] 521-28 (1999).

${ }^{6}$ F. F. Lange, "Powder Processing Science and Technology for Increased Reliability," J. Am. Ceram. Soc., 72 [1] 3-15 (1989).

${ }^{7}$ W. M. Sigmund, N. S. Bell, and L. Bergström, "Novel Powder-Processing Methods for Advanced Ceramics," J. Am. Ceram. Soc., 83 [7] 1557-74 (2000).

${ }^{8}$ J. A. Lewis, "Colloidal Processing of Ceramics," J. Am. Ceram. Soc., 83 [10] 2341-59 (2000).

${ }^{9} \mathrm{~K}$. Araki and J. W. Halloran, "A New Freeze-Casting Technique for Ceramics with Sublimable Vehicles," J. Am. Ceram. Soc., 87 [10] 1859-63 (2004).

${ }^{10}$ E. R. Herrmann, "Molding Comminuted Nonplastic Inorganic Material," U.S. Pat. No. $3330892,1967$.

${ }^{11}$ C. A. Sundback, B. E. Novich, A. E. Karas, and R. W. Adams, "Complex Ceramic and Metallic Shaped by Low Pressure Forming and Sublimative Drying," U.S. Pat. No. 5047 182, 1991.

${ }^{12}$ T. E. Daubert and R. P. Danner, Physical and Thermodynamic Properties of Pure Chemicals: Data Compilation, Part 4. Taylor and Francis Publishers, New York, 1989.

${ }^{13}$ J. E. Jordan (Ed.), Vapor Pressure of Organic Compounds. Interscientific Publishers, New York, 1954.

${ }^{14}$ R. C. Weast (Ed.), CRC Handbook of Chemistry and Physics, 50th ed. Chemical Rubber Co., Cleveland, OH, 1969.

${ }^{15}$ E. W. Washburn, C. J. West, N. E. Dorsey, F. R. Bichowsky, and A. Klemenc (Eds.), International Critical Tables of Numerical Data, Physics, Chemistry and Technology, 1st ed., Vol. 4; p. 180. McGraw-Hill, New York, 1928.

${ }^{16}$ P. M. Robinson, H. J. Rosell, and H. G. Scott, "Binary Phase Diagrams of Some Molecular Compounds-I," Mol. Cryst. Liq. Cryst., 10, 61-74 (1970).

${ }^{17}$ V. V. Podolinsky, "Non-reciprocal Heterogeneous Nucleation in Eutectic Systems," J. Cryst. Growth, 98, 838-42 (1989).

${ }^{18}$ L. M. Fabietti and R. Trivedi, "Nonequilibrium Effects during the Ledgewise Growth of a Solid-Liquid Interface," Metall. Trans. A, 22A, 1249-58 (1991).

${ }^{19}$ M.-J. Suk and K. Leonartz "Halo Growth during Unidirectional Solidification of Camphor-Naphthalene Eutectic System," J. Cryst. Growth, 213, 141-49 (2000).

${ }^{20}$ G. Q. Weaver and B. G. Nelson, "Molding Refractory and Metal Shapes by Slip-Casting," U.S. Pat. No. $4341725,1982$.

${ }^{21}$ M. A. Occhionero, B. E. Novich, and C. A. Sundback, "Forming of Complex High Performance Ceramic and Metallic Shapes," U.S. Pat. No. 5047 181, 1991.

${ }^{22}$ S. W. Sofie and F. Dogan, "Freeze Casting of Aqueous Alumina Slurries with Glycerol," J. Am. Ceram. Soc., 84 [7] 1459-64 (2001).

${ }^{23}$ D. R. Uhlmann, B. Chalmers, and K. A. Jackson, "Interaction between Particles and a Solid-Liquid Interface," J. Appl. Phys., 35, 2986-93 (1964).

${ }^{24} \mathrm{~K}$. Araki and J. W. Halloran, "Porous Ceramic Bodies with Interconnected Pore Channels by a Novel Freeze Casting Technique," J. Am. Ceram. Soc., in press. 